Article

\title{
Friendly Communities and Outdoor Spaces in Contexts of Urban Population Decline
}

\author{
M. Francisca Lima *, Catharine Ward Thompson $₫$ and Peter Aspinall \\ OPENspace Research Centre, University of Edinburgh, Lauriston Place, Edinburgh EH3 9DF, UK; \\ c.ward-thompson@ed.ac.uk (C.W.T.); p.a.aspinall@hw.ac.uk (P.A.) \\ * Correspondence: francisca.lima@ed.ac.uk; Tel.: +44-1316-515-801
}

Received: 9 October 2020; Accepted: 4 November 2020; Published: 10 November 2020

check for updates

\begin{abstract}
Urban population decline has been extensively described as a triggering factor for community segregation and fragmentation, as well as for land use vacancy and house/flat vacancies, resulting in rising interest in strategies of green infrastructure expansion aimed at citizens' wellbeing and urban ecosystems. However, city-scaled green infrastructures can be formed by different typologies of outdoor spaces, providing diverse social affordances that can impact community cohesion and resilience differently. This study focuses on the relationship between preferences for particular outdoor space typologies and for community friendliness, under contexts of urban population decline as a migratory process. In the context of Lisbon, a European capital-city experiencing migration and immigration but also urban population shrinkage in some areas of its metropolitan region, the study used conjoint analysis to test participants' preference for different attributes of their urban environment. The results showed a significant positive correlation, in the sample living in depopulating neighbourhoods, between preferences for friendlier communities and for outdoor spaces of an enclosed and protected character $(\mathrm{r}=0.34)$, compared with no significant correlation in the studied non-depopulating neighbourhoods. These results do not deny the importance of public parks of wide dimensions as a strategy for shrinking cities' green infrastructures but suggest that urban citizens living in depopulating neighbourhoods have a higher awareness of the importance of small-scale, enclosed outdoor/green spaces to give a stronger sense of social connectedness. This study contributes to the general literature on urban shrinkage by showing that these sensitive conditions can potentially change behaviour and use of public spaces in urban contexts.
\end{abstract}

Keywords: shrinking cities; community; green infrastructure; conjoint analysis; Lisbon

\section{Introduction: Friendly Communities in Depopulating Urban Contexts}

"Like a slow-motion Katrina" is how Allweil [1] presents urban shrinkage processes. Although not imposing the abrupt disruptions of an armed conflict, a flood or an earthquake, urban outmigration can have long term devastating consequences, normally triggered by economic downturns conducive to high rates of unemployment, poverty, in-place social segregation [2] and lower levels of social interaction [3].

Some of the recognised triggers for urban shrinkage are processes of de-industrialisation, peripherisation and post-socialism [4-7] that deepen a socio-economic declining cycle [5] characterised by poor job opportunities and out-migration of young and qualified residents, with strong and negative consequences on birth rates. Suburbanisation has also been described as conducive to urban shrinkage via slow and selective out-migration of urban dwellers to new housing developments in the peripheries of a city $[4,6,8,9]$.

Numerous pressures unfold from the processes described above, such as an increase in long-term household vacancies which leads to lower population densities, infrastructure under usage and 
inefficiencies, namely in energy use, water supply and sewage, transport networks, and social equipment distribution $[7,9,10]$. Such processes also lead to a drop in tax revenues and a decreased public capacity [11] to strongly invest in the local economy, in common services and in public outdoor spaces. These social, economic, and infrastructural imbalances will in turn have a strong impact on both segregation levels and on equity of access to public services and social interactions so important for these fragile communities.

Social interaction is, according to Gehl [12], the first stage towards the development of socially meaningful neighbouring relationships, characterised by more than superficial levels of greeting. Meaningful relationships can entail supportive actions such as borrowing and lending goods, tools or materials; providing emotional or personal support; or providing access to relevant information (Weiss, 1985, as cited by Unger and Wandersman [13]):

In the words of Fleming et al [14] "People get to know one another gradually, often through a succession of casual interactions that grow longer and more involved over time" (p. 329).

A developed network of stronger relationships endows robust social support to segregated communities [13] in what is entitled in this study a "friendly community", following the term used by participants in focus groups with residents of the studied depopulating neighbourhoods. This type of social relationship is the basis for good levels of social capital as well as collective efficacy at the neighbourhood level, that is, a strong social network of trust and mutual aid [15] that can, in turn, lead to a strong capacity to work together for a common good/objective that can better serve the community at stake [16-18]. This capacity to work together for a common good-collective efficacy-will enhance levels of order and upkeep [19], which are considered two of the five key factors for the image of a city for the public, according to Nasar [20], and place attachment [21]. Collective efficacy is also positively associated with lower levels of violence [22] and crime [23], a problem reported in several depopulating neighbourhoods [24]. Moreover, due to the progressively declining public revenue in depopulating urban contexts [5], the reduced maintenance of public outdoor spaces, in particular typologies such as large parks, can potentially deter their use due to higher levels of fear and insecurity, and therefore also limit access to the potential known benefits of contact with "nature" for citizens' health and wellbeing [25-27].

In these contexts, social capital and the consequent collective efficacy can play an increasingly relevant part in the resilience and upkeep of these urban contexts. Examples range from the "Sisters of the Soil" in Detroit [28], a group of women who produce food to provide their families and, in so doing, create a safer and greener community; the "Horta do Monte", where old and new inhabitants of a core depopulating neighbourhood in Lisbon test permaculture principles in a small and unused land parcel and, by doing so, actively engage in a spontaneous process of social interweaving (author's observations); or the occupation of an old military camp in Thessaloniki (Greece) to be used as an informal public park and agricultural field [29] in a process of land reclamation; and many others. The literature concerned with the opportunities to reinforce the value of green spaces in shrinking cities is both based on examples where the aim is to create a reinforced green infrastructure at the city scale $[30,31]$, as well as via the use of small parcels of land to rekindle community life or even its economic thriving [32].

However, it is precisely in depopulating contexts that an increasing lack of social resources is identified, due to the displacement of younger and better-skilled residents of child-bearing age [6,33,34], referred to as the "creative class" by Florida [35] (p. xiii), and it is under these circumstances that rich opportunities for social contact between the remaining residents could be a crucial asset. According to Fleming et al. [14], there are three principles that enhance social contact in the public realm: "the opportunity for passive social contact", the "proximity to others", and an "appropriate space to interact". Population density and spatial compositions affording more opportunity for interaction would seem, therefore, to be key aspects for social contact in the public realm, and again are especially at risk in urban population shrinking contexts. Observations by Jan Gehl [12], William Whyte [36], and Stephen Carr et al. [37] concluded that some of the most important space qualities to trigger social 
interaction are: (1) the key presence of seating areas with a view to pedestrian flows-mostly streets; (2) access to movable seating options opening the choice between sun and shade, or isolation and group gatherings; (3) the presence of a café or kiosk; (4) the presence of transitional spaces between the private and public realms; and (5) some level of spatial enclosure. According to Gehl [12], urban squares wider than 100 meters in dimension attract fewer transients and even fewer stop-byers than squares of more intimate dimensions, and Farida [38], not only corroborated this correlation between space enclosure and social interaction but has also found a correlation between extreme outdoor space openness and a lower sense of community. The comfort associated with the sense of enclosure fits well with the prospect-refuge theory elaborated by Jay Appleton [39], and observed by Gehl [12], in the need for people to position themselves in spaces where their backs are protected and simultaneously there is the presence of good views.

On the other hand, woodlands seem to be connected with equally important, but distinct affordances. Ward Thompson, et al. [40], have concluded that "feeling at peace", access to "fresh air", and having contact with "natural features" were some of the top space qualities explaining visits to woodlands, whereas "meeting friends" was not at the top of the list for woodland walkers. Hewlett et al. [41], have also confirmed that affordances for tranquillity were associated with "natural environments", "large open spaces", and the "presence of few people". This seems to indicate that wider and more natural outdoor spaces are attractive for other functions besides social interaction, and they seem to be effective tools for the health and wellbeing needs of citizens, namely the ones connected with mental health and stress relief [42,43], but less so for social interaction affordances. Coolen and Meesters [44], have concluded that, when confronted with the choice between one big, central park, a typology more closely perceived as "natural", and several small public green spaces, around two thirds (approximately $60 \%$ ) of their questioned participants preferred this latter option. In the same study, the meanings and affordances of private gardens and public green spaces, in general, were compared. The results show that, although there are some shared affordances—such as, "being outside", "freedom", "nature", or "playground" - the possibility to "contact nature" is a more prominent affordance/meaning in public green spaces than in private gardens and one that is closely and non-hierarchically linked with satisfaction with life and liveability. Thus, in the cited study, the public quality of spacious urban parks is associated with naturalness but, for particular social groups, visiting woodlands or more natural spaces can endow a sense of vulnerability or insecurity and, therefore, some groups may avoid them, such as women [44] or ethnic minorities [45]. In several European cities, social segregation in shrinking core neighbourhoods is often synonymous with high concentrations of immigrant communities, for example in Barcelona (Spain) [46], Athens (Greece) [47], Manchester (UK) [48], or Lisbon (Portugal) [49]. Previous literature on immigration and urban migration has pointed to the value of appropriate outdoor spaces such as communal parks or gardens to increase neighbourhood connections and sense of community [50,51]. If this is the case, then it is important for urban planners and designers to understand better how the design of outdoor space may support neighbourliness in contexts of urban migration, including shrinking population contexts.

The analysis of these associated, but distinct, comparisons of parks vs. small gardens, and of public vs. private outdoor spaces, suggest that social interaction may be enhanced by small and medium scale, shared outdoor spaces, while the public nature of larger green spaces such as parks adds an enriched perception of naturalness, which also has benefits for wellbeing. The question then arises as to whether, for communities under stressful conditions, such as those undergoing sharp population losses, the design and presence of different types of open spaces can have even more meaningful roles. For example, as in so many other deprived contexts, residents of shrinking neighbourhoods often face restrictions in mobility because of lack of access to both public and private transport [28], meaning that walkable access to amenities and places where urban social interaction is possible and safe, as in enclosed outdoor spaces, becomes an essential resource.

Are residents of depopulated environments drawn towards outdoor spaces that afford more social contact, where the factor of greenness is also present, compared with larger public parks, despite the 
latter's attractiveness as a natural environment? A study developed by Hadavi et al. [52], seems to corroborate this hypothesis. In this study, the participants living in an urban depopulating context in Chicago were presented with different photographic scenes of outdoor spaces and preferences were analysed. The results show that these participants preferred green spaces of smaller dimensions where they could both socialise and grow plants, but would the results have been different in a control group of participants living in non-depopulating urban contexts? This is the comparison that the present study aims to tackle.

The aim of this research is to understand if, under conditions of population decline in urban contexts, a positive correlation between preferences for a friendlier community and the presence of outdoor public spaces of enclosed and protected character is strengthened. Formulated as a question, this study asks: in a context of population decline, is the desire to maintain a friendly and close sense of community accompanied by a greater preference for enclosed public outdoor spaces that can support such community cohesion, compared with that found in communities which are stable or growing in population?

\section{Methodology: Conjoint Analysis}

The methodological approach chosen for this study was conjoint analysis, which is a particularly robust technique to better understand, and structure, people's preferences in different situations of real-life decision-making, whether in relation to objects, spaces or services. This methodology was used previously within this same research project and fuller details on the overall approach undertaken can be found published elsewhere [53]. This paper focuses on the particular relationship between the two attributes considered, namely, "community" and "open and green space typologies", and their respective levels; and moreover, it uses a correlation analysis to assess the data.

Conjoint analysis is a decompositional approach, meaning that instead of testing individual attributes of one compositional reality, participants are presented with predefined scenarios. with fixed combinations of attributes, with the possibility of choosing only one of those scenarios. After several of these tasks are completed, it is possible to calculate a hierarchy of more and less important attributes for the final choices of a particular participant by using a hierarchical Bayes logarithm. This information allows for sample and sub-sample analysis and comparisons. Adaptive Choice-Based Conjoint analysis $(\mathrm{ACBC})$, the latest version of conjoint analysis, was chosen in order to add some prior questions to the main study, allowing the presentation of a tailored set of scenarios to each participant, that is, scenarios that are closer to each participant's ideal scenario. These added questions allow for better predictions and for the use of smaller samples [54-56]. If using a traditional conjoint study (CBC), this particular study would require 95 respondents per sub-sample, but the work of Jervis and Drake [57] has shown that $\mathrm{ACBC}$ studies can achieve robust results with one-third of the sample size of a $\mathrm{CBC}$ study.

The structure of a conjoint analysis study is based on two concepts: attributes and levels, where an attribute is normally described through different levels. For example, if a study intends to better understand what people most value in a library, the attribute "lighting" could be tested and described as "natural light" (level 1) or "artificial light" (level 2), so this attribute is described through the use of two levels. To each of these levels, a participant's "utility values" are calculated, which are interval relative data, made to sum zero, that indicate the valuation given to each level of an attribute, when all levels of other attributes are made equal [53]. The development, application, and calculation of utilities were performed by the use of Sawtooth Market Tool (SMRT software) and the data was analysed with the use of SPSS.

The two attributes that this paper is specifically concerned with, are "community" and "open/green spaces type", that were described via the following levels, respectively: "my neighbours are my friends" (neighbours as friends); "my neighbours greet me and I greet them" (neighbours as acquaintances); "I do not know my neighbours" (neighbours as strangers); and, "squares and small gardens"; "private or semi-private lots"; "big public park" (see Figure 1). The descriptions of the levels of the attribute "community" were drawn from transcriptions of preliminary focus groups where these expressions 
were often used by different participants and different age groups. In the case of the attribute "open/green spaces type", the levels not only reflect the typologies of outdoor spaces that are more common in Lisbon city, that is, the "squares and small gardens" which are overwhelmingly present in the studied neighbourhoods, but also levels reflecting a greater degree of public use/openness and dimension/scale; therefore, we have tested small spaces of public use- "squares and small gardens", small spaces of private use-_"private and semi-private lots", and wide spaces of public use- "big public park". All these three tested outdoor typologies include some sense of contact with nature by the use of the words: "gardens", "private lots", and "parks", with the aim of testing social affordances of these spaces rather than levels of greenness.

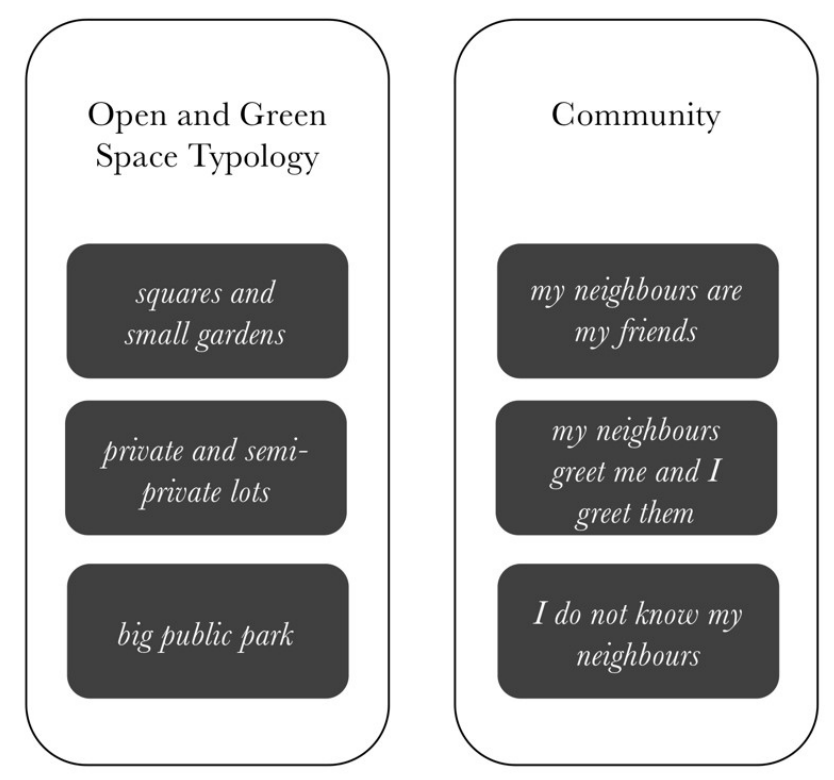

Figure 1. Attributes and levels considered.

A conjoint questionnaire was developed and piloted to ensure comprehensibility for participants and consistency of data collected, to be administered in three different groups of participants, namely participants living in depopulating contexts, participants living in growing contexts, and participants looking for a new house at the moment of the data collection in 2014. These participants were all living in Lisbon's Metropolitan Area, Portugal, at the time of data collection. The city of Lisbon has lost approximately 37\% of its resident population from 1981 until 2019, according to official Portuguese data (www.ine.pt and www.pordata.pt), bringing deep changes to the life of the city, which became increasingly abandoned and derelict up until 2014, the point at which a touristic surge invaded the city centre and re-activated some building renovation processes. The tourist economy, characterised by short term visitors and rentals, and the retail typologies that accompany these, has halted with the 2020 COVID-19 pandemic. This fact has made the abandoned nature of the city centre much more visible again [53]. The neighbourhoods for this study were selected based on demographic data from the previous three decades, and their similar urban features and socio-economic profiles [53]. A sense of enclosure is typical of the Lisbon's urban fabric and their public squares and small gardens, and the communities that still live in these neighbourhoods are dominated by older residents with comparatively low levels of education [53].

Two neighbourhoods were selected to represent urban population shrinkage: Santo Estevão and São Paulo; and a third one to represent the opposite phenomenon-urban population growth-Socorro. Also, a group featuring house searchers was studied as a control group, since citizens in this situation are expected to be less constrained in their preferences towards cityscapes, since they are in the process of choosing another dwelling situation, and therefore less at risk of a self-confirming process favouring the features of their current neighbourhoods. 
The questionnaires were computer-based, with some assistance being provided when needed to participants less comfortable with computer use. Participants were recruited in cafes, parishes, civic and recreational associations, or simply on the street. In total 130 questionnaires were collected, being distributed evenly throughout the three groups, namely the depopulating group $(\mathrm{N}=44)$, the growing population group $(\mathrm{N}=49)$, and the house searchers group $(\mathrm{N}=37)$. The analysis of the data was mainly concerned with comparisons of the correlation coefficients between the different levels of the attributes "community" and "open/green spaces type" throughout different dwelling groups. Demographic data such as age, gender, education, and children in the household, were also collected. More information on the questionnaire, sampling strategy, demographics of the sample, and data analysis is available in a previous publication [53]. The statistical tests performed have shown that, whereas the attribute "green space typology" is not affected by demographic variables, the attribute "community" is, with older and less educated participants being significantly more concerned about the friendliness of their neighbourhoods [53].

\section{Results}

To address the research question(s), a series of correlations were produced between the different levels of the attributes "community" and "open/green space type" by groups in different contexts: (1) living in depopulating neighbourhoods; (2) living in growing neighbourhoods; and (3) house searchers in Lisbon's metropolitan area. These correlations were tested using the non-parametric Spearmen test when one or two of the variables did not show normal distributions and the Pearson test when both variables showed a normal distribution when using the Kolmogorov-Smirnov test.

Table 1 shows that the only subgroup where the correlation between "squares and small gardens" and "neighbours as friends" is significant is the group of residents living in depopulating neighbourhoods (marked in orange in Figure 2). The correlation coefficient between these two levels is rs $=0.34(p=0.02)$ (Table 1) in the depopulating subgroup, showing a weak to moderate but significant association, whereas it is not significant in either of the other subgroups of study.

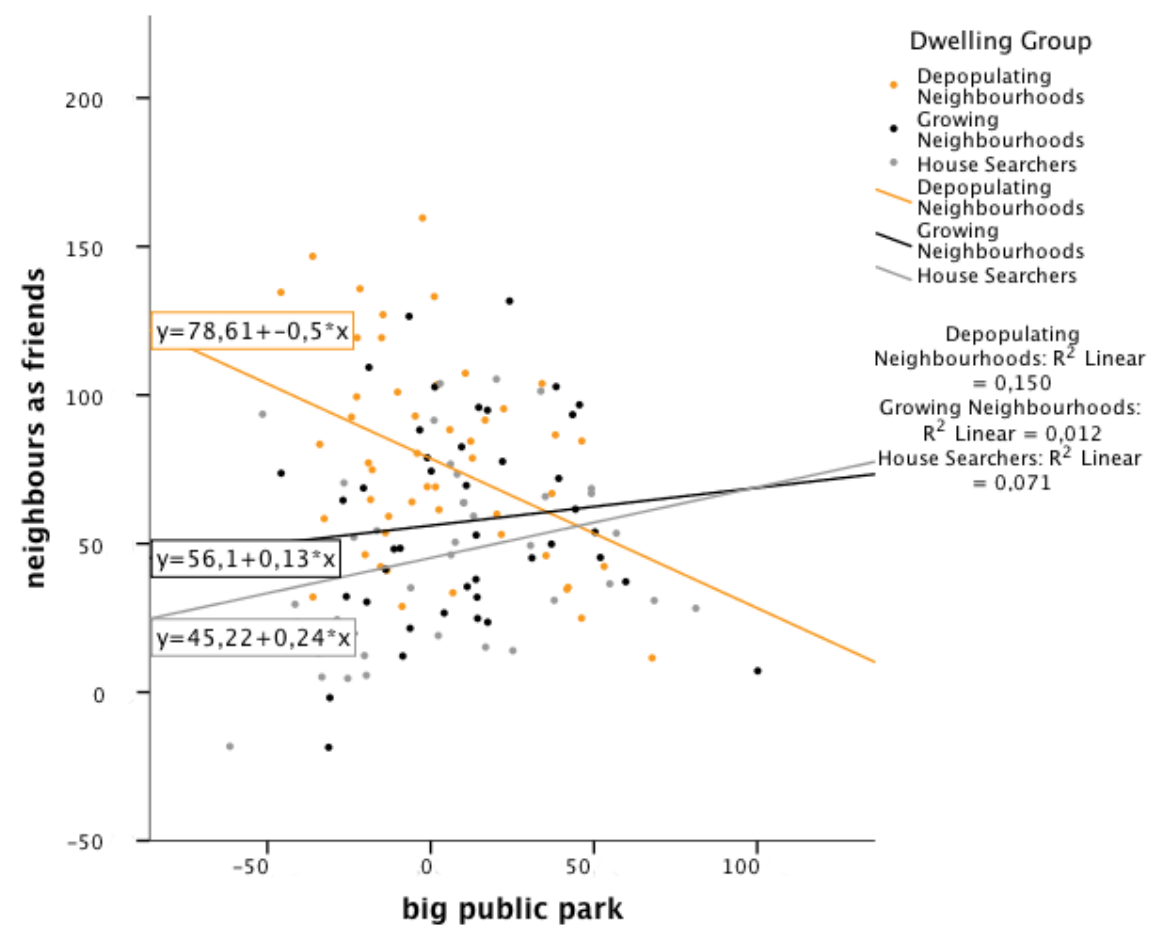

Figure 2. Correlations between the levels "big public park" and "neighbours as friends", according to the subgroups: "depopulating neighbourhoods", "growing neighbourhoods", and "house searchers" (Pearson test) showing the $\mathrm{R}^{2}$ levels. 
Table 1. Significance and correlation coefficients rs between the levels "squares and small gardens" and "neighbours as friends", according to the subgroups: "depopulating neighbourhoods", "growing neighbourhoods", and "house searchers".

\begin{tabular}{ccccc}
\hline \multicolumn{5}{c}{ Neighbours as Friends } \\
\hline & & N & rs (spearman) & $p$ \\
\hline \multirow{2}{*}{ Squares and small } & Depop. & 49 & 0.34 & 0.02 \\
gardens & Growing & 44 & 0.15 & n.s. \\
& House Searchers & 37 & 0.25 & n.s. \\
\hline
\end{tabular}

These results indicate a link between urban population decline and higher correlation coefficients between the preference for both friendlier communities and enclosed outdoor spaces, suggesting that small and enclosed open spaces are more attractive to participants that highly value close community support in depopulating urban contexts.

Conversely, and in line with the above finding, the correlation between the levels "squares and small gardens" and "neighbours as strangers" is more negatively expressed in depopulating urban environments. In fact, as Table 2 shows, this (negative) correlation is only significant in this subgroup, rs $=-0.33, p=0.00$ (Figure 3).

Table 2. Significance and correlation coefficients rs between the levels "squares and small gardens" and "neighbours as strangers", according to the subgroups: "depopulating neighbourhoods", "growing neighbourhoods", and "house searchers".

\begin{tabular}{ccccc}
\hline \multicolumn{5}{c}{ Neighbours as Strangers } \\
\hline & & N & rs (spearman) & $p$ \\
\hline \multirow{2}{*}{ Squares and small } & Depop & 49 & -0.33 & 0.00 \\
gardens & Growing & 44 & -0.08 & n.s. \\
& House Searchers & 37 & -0.22 & n.s. \\
\hline
\end{tabular}

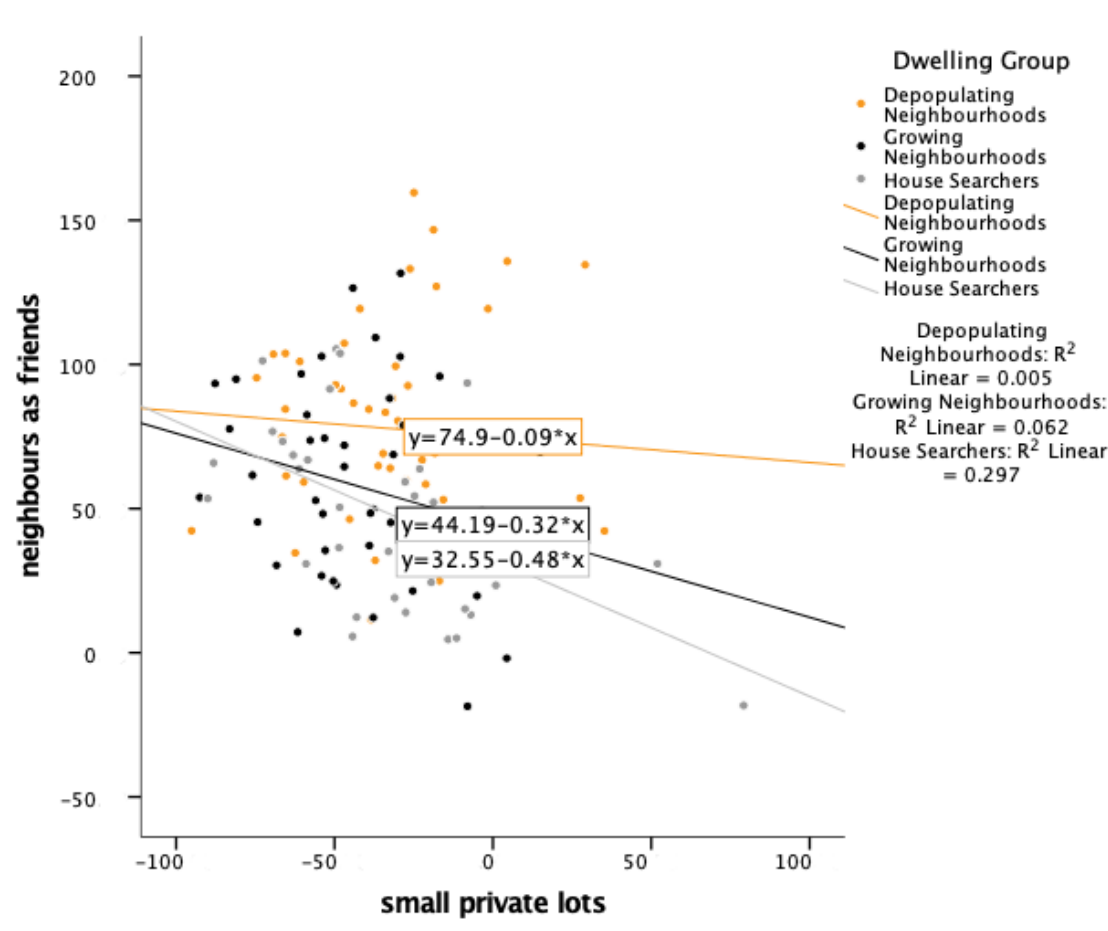

Figure 3. Correlations between the levels "private or semi-private lots" and "neighbours as friends", according to the subgroups: "depopulating neighbourhoods", "growing neighbourhoods", and "house searchers" (Pearson test) showing the R2 levels. 
In support of the hypothesis linking small, enclosed green spaces with the desire for friendly communities, Table 3 shows there is a significant negative correlation between the levels "big public park" and "neighbours as friends" in the group of participants that live in depopulating neighbourhoods, $\mathrm{r}=-0.39, p=0.01$, indicating that urban dwellers who value a friendly community do not simultaneously value having access to a big public park in their neighbourhood of residence.

Table 3. Significance and correlation coefficients rs between the levels "big public park" and "neighbours as friends", according to the subgroups: "depopulating neighbourhoods", "growing neighbourhoods", and "house searchers".

\begin{tabular}{lcccc}
\hline \multicolumn{5}{c}{ Neighbours as Friends } \\
& & N & r (pearson) & $p$ \\
\hline \multirow{3}{*}{ Big Public Park } & Depop & 49 & -0.39 & 0.01 \\
& Growing & 44 & 0.11 & n.s. \\
& House Searchers & 37 & 0.27 & n.s. \\
\hline
\end{tabular}

However, Table 4 shows that those living in depopulating neighbourhoods who value a more anonymous urban social context ("neighbours as strangers"), also value public parks as hypothetical green space typologies, $\mathrm{rs}=0.33 ; p=0.02$, whereas participants living in the other dwelling contexts do not show a significant correlation between these two levels.

Table 4. Significance and correlation coefficients rs between the levels "big public park" and "neighbours as strangers", according to the subgroups: "depopulating neighbourhoods", "growing neighbourhoods", and "house searchers".

\begin{tabular}{lcccc}
\hline \multicolumn{5}{c}{ Neighbours as Strangers } \\
& N & rs (spearman) & $p$ \\
\hline \multirow{3}{*}{ Big Public Park } & Depop & 49 & 0.33 & 0.02 \\
& Growing & 44 & -0.06 & n.s. \\
& House Searchers & 37 & -0.07 & n.s. \\
\hline
\end{tabular}

In the group of house searchers, Table 5 shows there is only one significant correlation between the different levels of the attributes "community" and "green space type", namely a negative correlation between the levels "neighbours as friends" and "small private and semi-private lots", $\mathrm{r}=-0.55$ (medium-size effect), $p=0.00$, meaning that, for these participants, valuing a friendlier community is linked with a low interest in access to private and semi-private outdoor spaces.

Table 5. Significance and correlation coefficients rs between the levels "small private and semi-private lots" and "neighbours as friends", according to the subgroups: "depopulating neighbourhoods", "growing neighbourhoods", and "house searchers".

\begin{tabular}{lcccc}
\hline \multicolumn{5}{c}{ Neighbours as Friends } \\
\hline & & N & rs (spearman) & $p$ \\
\hline \multirow{2}{*}{ Small private and } & Depop & 49 & -0.07 & n.s. \\
semi-private lots & Growing & 44 & -0.25 & n.s. \\
& House Searchers & 37 & -0.55 & 0.00 \\
\hline
\end{tabular}

In the house-searchers group, approximately $30 \%$ of the variability in the level "private or semi-private lots" results from the variability in the level "neighbours as friends", whereas these percentages are only $6 \%$ and $0.5 \%$ for the growing neighbourhoods and depopulating neighbourhoods respectively (see Figure 3). 
It is worth noting that the same relationship is not found significant for this group between the levels "neighbours as friends" and "public park" or between "neighbour as strangers" and "small private and semi-private lots". Although house searchers represented a range of socio-economic status, on average those participants in search of a new house/apartment were of a higher economic and educational background than the average for the other subgroups, which reflects in part the fact that these questionnaires were undertaken within a context of an economic crisis in Portugal, when banks tightened access to credit (2014).

Interestingly, for participants living in growing neighbourhoods, there are no significant correlations between any of the levels of the attributes in focus.

These results support the study hypothesis, showing urban population decline as an enhancing factor, strengthening the relationship between preference for a closer and friendlier community and preference for small and protected outdoor spaces such as squares and small gardens. By contrast, population shrinkage seems to disfavour the importance of private or semi-private settings for outdoor experiences, suggesting that, under these circumstances, smaller green space typologies open to the community bring a particularly welcoming affordance.

\section{Discussion}

This study offers evidence that, where urban populations are in flux due to inward and outward migration in different neighbourhoods, population loss is a relevant factor in the relationship between preferences for friendlier communities and preferences for particular outdoor space typologies. Although a correlation between preference for enclosed and small-scale spaces and for friendlier communities is present when the sample is considered as a whole, it is the sub-sample of participants living in depopulating environments that contributes most to this general outcome, when compared with non-depopulating contexts. The sample of house/flat searchers offered a comparative control group, less constrained by potential confirmation bias aligning preferences to actual dwelling conditions. The correlation between preference for smaller and enclosed outdoor spaces and for friendlier communities was not identified in either participant group living in non-depopulating environments or in participants searching for a house. This suggests that living in a fragmenting community experiencing outward migration might trigger stronger preferences for physical and social reinforcement of particular types of public outdoor community spaces, namely, small and enclosed ones. Conversely, such participants, in depopulating communities that value a friendlier community highly, do not seem to share a particular interest in having access to public parks of wider dimensions.

All of the neighbourhoods where these questionnaire surveys took place are dense, irregularly laid out, human-scaled, and dominated by small, protected, and enclosed outdoor spaces. This fact might have played a confirmation bias role for participants' preferences. However, although these spatial features were closely similar in all the studied neighbourhoods, the sample of participants living in the growing population neighbourhood did not present a significant correlation between the different levels of the attributes "community" and "open space type". This supports the study hypothesis that neighbourhoods' shrinkage can lead to a stronger desire for community cohesion and for the spaces that might reinforce social interaction. This increased social interaction, potentially conducive to higher levels of social capital and collective efficacy, can, in turn, reinforce the processes of neighbourhood safety and upkeep, with positive consequences in place attachment and potentially in neighbourhood desirability [16,19-21], although community attachment alone, according to Mahmoudi Farahani [58], can be an enhancing factor for a sense of safety, identity, participation, mental health, and wellbeing.

The conclusions of this study are based on correlations and so cannot demonstrate direct cause and effect, an acknowledged limitation of such cross-sectional studies. However, regression analyses from this same study and published elsewhere showed that the sample living in depopulating neighbourhoods has a significantly higher preference for friendlier communities, compared with the other sample groups, even when factors such as education level, age, gender, and presence of children in the household were controlled for [53]. The correlational analysis presented here corroborates the 
regression analysis mentioned above, that is, the higher importance of the factor "community" for depopulating communities seems to reflect an aspiration for a cohesive and supportive social structure. Although urban shrinkage can open opportunities for green infrastructure reinforcement aimed at a more balanced urban and regional ecological stability [30,31], and for new economic activities [32], it also opens the need for a reinforced sense of community and for the urban typologies that afford it, that is, enclosed public outdoor spaces appropriately linked and intertwined with the structure of urban life. If these same enclosed outdoor spaces can also endow meaningful contact with natural elements, known to be beneficial for people's health and wellbeing [25-27], which is at greater risk in deprived and shrinking communities, then there is the possibility of creating a doubly beneficial structure for these neighbourhoods.

Further investigations on the use of different outdoor typologies by the sub-groups studied here would be of interest to compare with these results, namely in a new worldwide context: (1) how COVID-19 could deepen the processes of core city neighbourhood shrinkage, leaving the most fragile, elderly, and less privileged behind [59,60]; and (2) how social distancing advice could change these dwellers' perspectives on what constitutes an ideal dwelling settlement.

\section{Conclusions}

As hypothesised, this study suggests that green open space typologies are related to social preferences for friendly contact with others, corroborating previous studies and observations of human behaviour in public spaces. It also confirms that, within a depopulating context, preferences for smaller and enclosed outdoor spaces are correlated with preferences for a friendly community. However, the particular contribution of this study is the comparison between groups from depopulating and non-depopulating neighbourhoods of similar built environmental characteristics, within the same city. The results show an enhanced and significant preference for small and protected outdoor spaces in shrinking urban contexts compared with non-shrinking ones. It can be assumed, therefore, that these different space typologies afford different social roles, or at least are regarded as doing so, by urban citizens. Clearly, friendly social interaction is a highly regarded affordance in these contexts, especially for those experiencing population decline. David Sloan Wilson [61] has suggested that altruism is not only an evolutionary advantage for communities but also an innate characteristic of human beings. This view of human beings' altruism further supports the theory of social capital, that communities faced with difficult times show more resilience when functioning within one common system of inter-supportiveness [61] for which it is important to ensure an urban context that can afford physical proximity and interaction to support the necessary social cohesion [12].

These results are relevant for the ongoing discussion regarding how green infrastructure reinforcement can be applied in depopulating cities. They are also relevant for the opposing challenges brought about by the COVID-19 pandemic, where both social engagement and personal distance are needed simultaneously. A follow-up study under these conditions is underway. However, according to the study presented here, for participants desiring friendly communities, the presence of communal (rather than private) green spaces of a small and enclosed nature, affording more social interaction is preferred to larger public parks. This seems to indicate that, at least in part, new green infrastructure in depopulating urban contexts should be developed to include small and protected communal outdoor spaces. Wide, natural park-like spaces fulfil different roles, namely stress relief and mental health improvement, as suggested by the literature [62-64], but the social closeness component of well-being afforded by friendly communities seems to be particularly relevant for depopulating communities.

In this way, the need for spaces that support friendly social interaction at community scale should be highlighted, particularly in these depopulating contexts, even if there is a wider green infrastructure development strategy being implemented simultaneously. These small spaces of community interaction can be of crucial value, particularly for fragile communities of those left behind by local or larger scale migratory processes. 
Author Contributions: Conceptualization, M.F.L.; Methodology M.F.L., P.A., C.W.T.; Data Collection and Curation, M.F.L.; Formal Analysis, M.F.L., P.A., C.W.T.; Writing-Original Draft Preparation, M.F.L.; Writing-Review and Editing, M.F.L., C.W.T. and P.A.; Visualization, M.F.L.; Funding Acquisition, M.F.L. All authors have read and agreed to the published version of the manuscript.

Funding: This research was funded by the Foundation for Science and Technology Portugal (FCT) under the Grant SFRH/BD/72394/2010. https://www.fct.pt; and supported by Sawtooth Software Ltd.

Acknowledgments: We are grateful for the support of Sawtooth Ltd. for granting a free academic licence to sawtooth software. We are also grateful to Maria Teles and Mariana Lemos, as well as to all the participants who generously shared their time with us.

Conflicts of Interest: The authors declare no conflict of interest.

\section{References}

1. Allweil, Y. Shrinking Cities: Like a Slow-Motion Katrina. Places 2007, 19, 91-94.

2. Großmann, K.; Arndt, T.; Haase, A.; Rink, D.; Steinführer, A. The influence of housing oversupply on residential segregation: Exploring the post-socialist city of Leipzig. Urban Geogr. 2015, 36, 550-577. [CrossRef]

3. Istrate, A.-L.; Bosák, V.; Nováček, A.; Slach, O. How attractive for walking are the main streets of a Shrinking city? Sustainability 2020, 12, 6060. [CrossRef]

4. Audirac, I.; Fol, S.; Martinez-Fernandez, C. Shrinking Cities in a Time of Crisis. Berkeley Plan. J. 2011, 23, 51-57. [CrossRef]

5. Fritsche, M.; Endlicher, W. Shrinking Cities: A New Challenge for Research in Urban Ecology. In Shrinking Cities: Effects on Urban Ecology and Challenges for Urban Development; Langner, M., Endlicher, W., Eds.; Peter Lang: New York, NY, USA, 2007; pp. 17-33.

6. Oswalt, P. Shrinking Cities. In Shrinking Cities; Oswalt, P., Ed.; Project Office Philipp Oswalt: Berlin, Germany, 2008; pp. 3-28.

7. Reckien, D.; Martinez-Fernandez, C. Why Do Cities Shrink? Eur. Plan. Stud. 2011, 19, 1375-1397. [CrossRef]

8. Hollander, J.B.; Schwarz, T.; Popper, F.J.; Hollander, J.B. Planning Shrinking Cities. Prog. Plan. 2009, 72, 223-232.

9. Rink, D.; Haase, A.; Bernt, M.; Grossmannn, K. Shrink Smart: The Governance of Shrinkage within a European Context; Helmholtz-Zentrum Fur Umweltforschung: Leipzig, Germany, 2012.

10. European Environmental Agency. Ensuring Quality of Life in Europe's Cities and Towns; EEA (European Environment Agency) Report No 5; Office for Official Publications of the EU: Luxembourg, 2009.

11. Herrmann, D.L.; Shuster, W.; Mayer, A.L.; Garmestani, A.S. Sustainability for shrinking cities. Sustainability 2016, 8, 911. [CrossRef]

12. Gehl, J. Life between Buildings; Van Nostrand Reinhold Company: New York, NY, USA, 1980.

13. Unger, D.G.; Wandersman, A. The importance of neighbors: The social, cognitive, and affective components of neighboring. Am. J. Community Psychol. 1985, 13, 139-169. [CrossRef]

14. Fleming, R.; Baum, A.; Singer, J.E. Social support and the physical environment. In Social Support and Health; Academic Press, Inc.: London, UK, 1985.

15. Kawachi, I. Social Capital and Community Effects on Population and Individual Health. Ann. NY Acad. Sci. 1999, 896, 120-130. [CrossRef]

16. Manzo, L.C. Finding Common Ground: The Importance of Place Attachment to Community Participation and Planning. J. Plan. Lit. 2006, 20, 335-350. [CrossRef]

17. Sampson, R. Neighbourhood and community: Collective efficacy and community safety. New Econ. 2004, 11, 106-113. [CrossRef]

18. Barnett, G. Encyclopedia of Social Networks; SAGE Publications, Inc.: Thousand Oaks, CA, USA, 2011. [CrossRef]

19. Walton, E. "It's Not Just a Bunch of Buildings": Social Psychological Investment, Sense of Community, and Collective Efficacy in a Multiethnic Low-Income Neighborhood. City Community 2016, 15, 231-263. [CrossRef]

20. Nasar, J.L. The Evaluative Image of the City. J. Am. Plan. Assoc. 1990, 56, 41-53. [CrossRef]

21. Brown, B. Place attachment in a revitalizing neighborhood: Individual and block levels of analysis. J. Environ. Psychol. 2003, 23, 259-271. [CrossRef] 
22. Sampson, R.J. Neighborhoods and Violent Crime: A Multilevel Study of Collective Efficacy. Science 1997, 277, 918-924. [CrossRef]

23. Rosenbaum, D.P. Community crime prevention: A review and synthesis of the literature. Justice Q. 1988, 5, 323-395. [CrossRef]

24. Frazier, A.E.; Bagchi-Sen, S.; Knight, J. The spatio-temporal impacts of demolition land use policy and crime in a shrinking city. Appl. Geogr. 2013, 41, 55-64. [CrossRef]

25. Mitchell, R.; Popham, F. Effect of exposure to natural environment on health inequalities: An observational population study. Lancet 2008, 372, 1655-1660. [CrossRef]

26. Ulrich, R.S. Human responses to vegetation and landscapes. Landsc. Urban Plan. 1986, 13, 29-44. [CrossRef]

27. Ward Thompson, C.; Silveirinha de Oliveira, E. Evidence on health benefits of urban green spaces. In Urban Green Spaces and Health: A Review of Evidence; Egorov, A., Mudu, P., Braubach, M., Martuzzi, M., Eds.; World Health Organisation Regional Office for Europe: Copenhagen, Denmark, 2016; pp. 3-20.

28. White, M.M. Sisters of the Soil: Urban Gardening as Resistance in Detroit. Race/Ethn. Multidiscip. Glob. Contexts 2011, 5, 13-28. [CrossRef]

29. Athanassiou, E. The hybrid landscape of public space in Thessaloniki in the context of crisis. Landsc. Res. 2017, 42, 782-794. [CrossRef]

30. Haase, D. Shrinking Cities, Biodiversity and Ecosystem Services. In Urbanization, Biodiversity and Ecosystem Services: Challenges and Opportunities; Solecki, W., Marcotullio, P.J., Eds.; Springer: New York, NY, USA, 2013; pp. 485-504. [CrossRef]

31. Haase, D.; Haase, A.; Rink, D. Conceptualizing the nexus between urban shrinkage and ecosystem services. Landsc. Urban Plan. 2014, 132, 159-169. [CrossRef]

32. Pallagst, K.; Vargas-Hernández, J.; Hammer, P. Green innovation areas-En route to sustainability for shrinking cities? Sustainability 2019, 11, 6674. [CrossRef]

33. Martinez-Fernandez, C.; Martinez-Fernandez, C.; Kubo, N.; Noya, A.; Weyman, T. Demographic Change and Local Development: Shrinkage, Regeneration and Social Dynamics; OECD/LEEDS: Paris, France, 2012.

34. Schatz, L.K. What Helps or Hinders the Adoption of 'Good Planning' Principles in Shrinking Cities? A Comparison of Recent Planning Exercises in Sudbury, Ontario and Youngstown, Ohio, Challenges; University of Waterloo: Waterloo, ON, Canada, 2010.

35. Florida, R. The Rise of the Creative Class; Basic Books: New York, NY, USA, 2002.

36. Whyte, W.H. The Social Life of Small Urban Spaces; The Conservation Foundation: Baltimore, MD, USA, 1980.

37. Carr, S.; Francis, M.; Rivlin, L.G.; Stone, A.M. Public Space; Cambridge University Press: Cambridge, UK, 1992. Available online: https://books.google.pt/books?id=pjo4AAAAIAAJ\&printsec=frontcover\&hl=pt-PT\& source $=$ gbs_ge_summary_r\&cad $=0 \# \mathrm{v}=$ onepage $\& \mathrm{q} \& \mathrm{f}=$ false (accessed on 17 September 2013).

38. Farida, N. Effects of outdoor shared spaces on social interaction in a housing estate in Algeria. Front. Archit. Res. 2013, 2, 457-467. [CrossRef]

39. Appleton, J. Prospects and refuges re-visited. Landscape 1984, 3, 91-103. [CrossRef]

40. Thompson, C.W.; Aspinall, P.; Bell, S.; Findlay, C. "It Gets You Away From Everyday Life": Local Woodlands and Community Use-What Makes a Difference? Landsc. Res. 2005, 30, 109-146. [CrossRef]

41. Hewlett, D.; Harding, L.; Munro, T.; Terradillos, A.; Wilkinson, K. Broadly engaging with tranquility in protected landscapes: A matter of perspective identified in GIS. Landsc. Urban Plan. 2017, 158, 185-201. [CrossRef]

42. Ward Thompson, C.; Roe, J.; Aspinall, P. Woodland improvements in deprived urban communities: What impact do they have on people's activities and quality of life? Landsc. Urban Plan. 2013, 118, 79-89. [CrossRef]

43. Roe, J.J.; Thompson, C.W.; Aspinall, P.A.; Brewer, M.J.; Duff, E.I.; Miller, D.; Mitchell, R.; Clow, A. Green Space and Stress: Evidence from Cortisol Measures in Deprived Urban Communities. Int. J. Environ. Res. Public Health 2013, 10, 4086-4103. [CrossRef]

44. Coolen, H.; Meesters, J. Private and public green spaces: Meaningful but different settings. J. Hous. Built Environ. 2012, 27, 49-67. [CrossRef]

45. Bell, S. Nature for People: The Importance of Green Spaces to Communities in the East Midlands of England. In Wild Urban Woodlands: New Perspectives for Urban Forestry; Kowarik, I., Korner, S., Eds.; Springer: Berlin/Heidelberg, Germany, 2005; pp. 81-94.

46. Dura-Guimera, A. Population deconcentration and social restructuring in Barcelona, a European Mediterranean city. Cities 2003, 20, 387-394. [CrossRef] 
47. Panori, A.; Psycharis, Y.; Ballas, D. Spatial segregation and migration in the city of Athens: Investigating the evolution of urban socio-spatial immigrant structures. Popul. Space Place 2018, 1-13. [CrossRef]

48. Brown, L.; Cunningham, N. The inner geographies of a migrant gateway: Mapping the built environment and the dynamics of caribbean mobility in Manchester, 1951-2011. Soc. Sci. Hist. 2016, 40, 93-120. [CrossRef]

49. Oliveira, N.; Padilla, B. Integrating superdiversity in urban governance: The case of inner-city Lisbon. Policy Politics 2017, 45, 605-622. [CrossRef]

50. Oliveira, E. Immigrants and public open spaces in Portugal. Revista Migrações 2009, 4, 109-133.

51. Tchoukaleyska, R. Public space and memories of migration: Erasing diversity through urban redevelopment in France. Soc. Cult. Geogr. 2016, 17, 1101-1119. [CrossRef]

52. Hadavi, S.; Kaplan, R.; Hunter, M.C.R. Environmental affordances: A practical approach for design of nearby outdoor settings in urban residential areas. Landsc. Urban Plan. 2015, 134, 19-32. [CrossRef]

53. Lima, M.F.; Ward Thompson, C.; Aspinall, P.; Bell, S. Communities facing urban depopulation: Exploring people's environmental preferences. A case study of Lisbon, Portugal. Cities Health 2020. [CrossRef]

54. Curry, J. Sawtooth Software Understanding Conjoint Analysis in 15 Minutes, Quirk's Marketing Research Review. Research Paper Series. 1996. Available online: http://www.sawtoothsoftware.com/support/ technical-papers/general-conjoint-analysis/understanding-conjoint-analysis-in-15-minutes-1996 (accessed on 24 July 2013).

55. Johnson, R.M.; Orme, B.K. A New Approach to Adaptive CBC. Research Paper Series. 2007. Available online: https://www.sawtoothsoftware.com/support/technical-papers/adaptive-cbc-papers/a-new-approachto-adaptive-cbc-2007 (accessed on 18 September 2013).

56. Orme, B.K.; Johnson, R.M. Testing Adaptive CBC: Shorter Questionnaires and BYO vs. 'Most Likelies'. Research Paper Series. 2008. Available online: http://www.sawtoothsoftware.com/support/technical-papers/ adaptive-cbc-papers/testing-adaptive-cbc-shorter-questionnaires-and-byo-vs-most-likelies-2008 (accessed on 17 September 2013).

57. Jervis, S.M.; Ennis, J.M.; Drake, M.A. A Comparison of Adaptive Choice-Based Conjoint and Choice-Based Conjoint to Determine Key Choice Attributes of Sour Cream with Limited Sample Size. J. Sens. Stud. 2012, 27, 451-462. [CrossRef]

58. Mahmoudi Farahani, L. The Value of the Sense of Community and Neighbouring. Hous. Theory Soc. 2016, 33, 357-376. [CrossRef]

59. Booth, R. Covid19 sparks exodus of middle class Londoners in search of the good life. The Guardian, 24 June 2020.

60. Williams, D. Coronavirus and the new exodus from Paris. The Economist, 9 April 2020; 2020.

61. Wilson, D.S. Does Altruism Exist? Yale University Press: New Haven, CT, USA, 2015.

62. Hansmann, R.; Hug, S.-M.; Seeland, K. Restoration and stress relief through physical activities in forests and parks. Urban For. Urban Green. 2007, 6, 213-225. [CrossRef]

63. Thompson, C.W.; Roe, J.J.; Aspinall, P.; Mitchell, R.; Clow, A.; Miller, D. More green space is linked to less stress in deprived communities: Evidence from salivary cortisol patterns. Landsc. Urban Plan. 2012, 105, 221-229. [CrossRef]

64. Ward Thompson, C.; Aspinall, P. Natural Environments and their Impact on Activity, Health, and Quality of Life. Appl. Psychol. Health Well Being 2011, 3, 230-260. [CrossRef]

Publisher's Note: MDPI stays neutral with regard to jurisdictional claims in published maps and institutional affiliations.

(C) 2020 by the authors. Licensee MDPI, Basel, Switzerland. This article is an open access article distributed under the terms and conditions of the Creative Commons Attribution (CC BY) license (http://creativecommons.org/licenses/by/4.0/). 